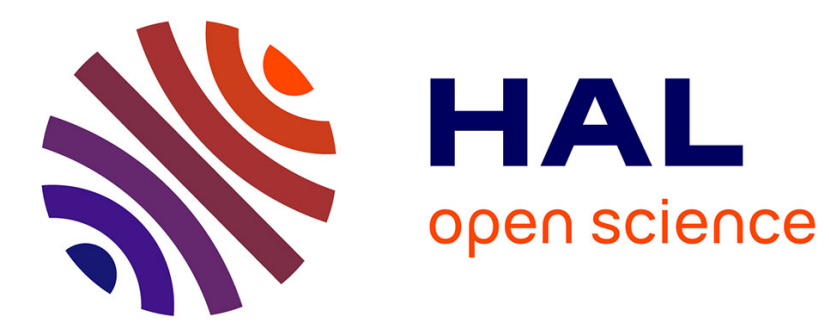

\title{
Untangling biogeochemical processes from the impact of ocean circulation: First insight on the Mediterranean dissolved barium dynamics
}

\author{
Loïc Jullion, Stéphanie Jacquet, T. Tanhua
}

\section{- To cite this version:}

Loïc Jullion, Stéphanie Jacquet, T. Tanhua. Untangling biogeochemical processes from the impact of ocean circulation: First insight on the Mediterranean dissolved barium dynamics. Global Biogeochemical Cycles, 2017, 31 (8), pp.1256 - 1270. 10.1002/2016GB005489 . hal-01621956

\section{HAL Id: hal-01621956 \\ https://hal-amu.archives-ouvertes.fr/hal-01621956}

Submitted on 15 May 2021

HAL is a multi-disciplinary open access archive for the deposit and dissemination of scientific research documents, whether they are published or not. The documents may come from teaching and research institutions in France or abroad, or from public or private research centers.
L'archive ouverte pluridisciplinaire HAL, est destinée au dépôt et à la diffusion de documents scientifiques de niveau recherche, publiés ou non, émanant des établissements d'enseignement et de recherche français ou étrangers, des laboratoires publics ou privés. 


\section{Global Biogeochemical Cycles}

\section{RESEARCH ARTICLE \\ 10.1002/2016GB005489 \\ Key Points: \\ Untangling biogeochemical processes from the impact of ocean circulation: First insight on the Mediterranean dissolved barium dynamics}

- Background D_Ba distribution reflects the balance between the overturning circulation and biogeochemical processes over long time scales - Significant depletion compared with the D_Ba background in the mesopelagic interior indicates organic carbon remineralization horizons

- Water mass framework is a powerful tool to better understand biogeochemical elements distribution and build robust geochemical tracers

Supporting Information:

- Supporting Information S1

- Figure S1

- Figure S2

- Figure S3

Correspondence to:

L. Jullion,

loicjullion@gmail.com

Citation:

Jullion, L., S. H. M. Jacquet, and T. Tanhua (2017), Untangling biogeochemical processes from the impact of ocean circulation: First insight on the Mediterranean dissolved barium dynamics, Global Biogeochem. Cycles, 31, 1256-1270, doi:10.1002/2016GB005489.

Received 27 JUL 2016

Accepted 14 JUL 2017

Accepted article online 19 JUL 2017 Published online 15 AUG 2017

(2)2017. American Geophysical Union. All Rights Reserved.

\author{
L. Jullion ${ }^{1}$, S. H. M. Jacquet ${ }^{1}$, and T. Tanhua ${ }^{2}(\mathbb{D}$ \\ ${ }^{1}$ Aix Marseille Univ, Université de Toulon, CNRS, IRD, MIO UM 110, Marseille, France, ${ }^{2}$ Marine Biogeochemistry, GEOMAR \\ Helmholtz Centre for Ocean Research Kiel, Kiel, Germany
}

Abstract Based on an unprecedented dissolved barium (D_Ba) data set collected in the Mediterranean Sea during a zonal transect between the Lebanon coast and Gibraltar (M84/3 cruise, April 2011), we decompose the D_Ba distribution to isolate the contribution of biogeochemical processes from the impact of the oceanic circulation. We have built a simple parametric water mass analysis (Parametric Optimum Multiparameter analysis) to reconstruct the contribution of the different Mediterranean water masses to the thermohaline structure. These water mass fractions have then been used to successfully reconstruct the background vertical gradient of D_Ba reflecting the balance between the large-scale oceanic circulation and the biological activity over long time scales. Superimposed on the background field, several D_Ba anomalies have been identified. Positive anomalies are associated with topographic obstacles and may be explained by the dissolution of particulate biogenic barium (P_Ba barite) of material resuspended by the local currents. The derived dissolution rates range from 0.06 to $0.21 \mu \mathrm{mol} \mathrm{m}^{-2} \mathrm{~d}^{-1}$. Negative anomalies are present in the mesopelagic region of the western and eastern basins (except in the easternmost Levantine basin) as well as in the abyssal western basin. This represents the first quantification of the nonconservative component of the D_Ba signal. These mesopelagic anomalies could reflect the subtraction of D_Ba during P_Ba barite formation occurring during organic carbon remineralization. The deep anomalies may potentially reflect the transport of material toward the deep sea during winter deep convection and the subsequent remineralization. The $D \_B a$ subtraction fluxes range from -0.07 to $-1.28 \mu \mathrm{mol} \mathrm{m} \mathrm{m}^{-2} \mathrm{~d}^{-1}$. D_Ba-derived fluxes of $\mathrm{P} \_$Ba barite (up to $0.21 \mu \mathrm{mol} \mathrm{m}^{-2} \mathrm{~d}^{-1}$ ) and organic carbon (13 to $29 \mathrm{mmol} \mathrm{C}^{-2} \mathrm{~d}^{-1}$ ) are in good agreement with other independent measurements suggesting that D_Ba can help constrain remineralization horizons. This study highlights the importance of quantifying the impact of the large-scale oceanic circulation in order to better understand the biogeochemical cycling of elements and to build reliable geochemical proxies.

\section{Introduction}

The large-scale oceanic distribution of biogeochemical properties reflects the action of processes associated with the biological pump on element cycling against the blending effect of the overturning circulation. Thus, one of the fundamental challenges to better understand oceanic biogeochemical cycles and to build robust geochemical tracers is to discriminate the relative contribution of conservative processes (oceanic circulation) from nonconservative processes (biogeochemistry) on the distribution of elements. One of the main applications of these tracers is to better constrain the carbon transfer efficiency and storage in the water column.

Among these biogeochemical tracers, particulate biogenic barium $\left(\mathrm{P} \_\mathrm{Ba}\right.$ barite- $\left.\mathrm{BaSO}_{4}\right)$ is one of the few proxies used to estimate organic carbon remineralization in the mesopelagic interior (100-1000 m) [Dehairs et al., 1980, 1997, 2008; Cardinal et al., 2001, 2005; Jacquet et al., 2005, 2007a, 2008a, 2008b, 2011, 2015; Stroobants et al., 1991]. Studies have shown that in a global ocean undersaturated with respect to barite [Monnin et al., 1999; Monnin and Cividini, 2006], P_Ba barite mainly precipitates in the mesopelagic zone inside oversaturated biogenic microenvironments during organic matter degradation by marine prokaryotes [Dehairs et al., 1980, 1997, 2000; Collier and Edmond, 1984; Bertram and Cowen, 1997; Bishop, 1988; Ganeshram et al., 2003]. Based on Ba-isotopic compositions, Horner et al. [2015] reported in the South Atlantic that barite formation should occur above $600 \mathrm{~m}$ depth range. 
However, the global barium cycle is not yet fully understood. In particular, the interactions between particulate and dissolved Ba phases and how they interact during barite formation in the water column remain an open question. The background distribution of dissolved barium ( $\left.D \_B a\right)$ that mirrors the one of nutrients and alkalinity [Chan et al., 1977; Lea and Boyle, 1989; Lea, 1993; Jeandel et al., 1996; Jacquet et al., 2005, 2007b; Hoppema et al., 2010] hints at these interactions. In particular, observed subsurface D_Ba depletions have been proposed to reflect the subtraction of $D \_B a$ from the ambient solution during biogenic $P \_B a$ formation [Collier and Edmond, 1984; Jacquet et al., 2005, 2007b, 2016]. A first attempt at this question was done by comparing the temporal change of dissolved and particulate Ba contents and calculating the degree of Ba mass conservation [Jacquet et al., 2007b]. In this study, we further investigate this question by explicitly accounting for the impact of the oceanic circulation on the D_Ba distribution in order to estimate the nonconservative part of the D_Ba signal that can potentially be attributed to $P_{-}$Ba barite formation. The overarching goal of this work is to further constrain the use of the barium proxy as a tracer of the organic carbon remineralization.

In this prospect, the Mediterranean Sea represents a unique case study. First, observations of the various components of the Mediterranean biological carbon pump provide organic carbon fluxes varying by at least 1 order of magnitude [Santinelli et al., 2010; Sternberg et al., 2007], highlighting the need to better balance the regional carbon budget [Malanotte-Rizzoli et al., 2014]. Second, due to limited exchanges with adjacent basins and the existence of an intense overturning circulation qualitatively resembling the global one but characterized by shorter time scales, the Mediterranean Sea is often considered as a laboratory to observe and understand the impact of transient climate variability on ecosystems and biogeochemical cycles [Malanotte-Rizzoli et al., 2014]. The occurrence of drastic changes in the thermohaline properties of the bottom water of the western and eastern basins [Roether et al., 2007; Schroeder et al., 2008; Schneider et al., 2014] in the 1990s and 2000s as well as expected future changes in key aspects of the overturning circulation (e.g., increased stratification, salinity [Somot et al., 2006; Adloff et al., 2015]) raise open questions about the impact of these changes on the carbon dynamics.

This study is based on an unprecedented D_Ba data set recently described by Jacquet et al. [2016] who showed that the general zonal distribution of D_Ba is impacted by both the large-scale Mediterranean circulation and biogeochemical processes. Here we decompose the Mediterranean D_Ba distribution in order to isolate the contribution of biogeochemical processing from the impact of circulation. The paper is divided into three parts. First, the conservative part on the D_Ba distribution, i.e., the part of the observed D_Ba at each location that can be attributed to mixing only, was identified. The mixing patterns were obtained by means of a modified optimum multiparameter (OMP) analysis (Parametric OMP (POMP)) [de Brauwere et al., 2007] applied to measured conservative tracers (potential temperature and salinity) and quasi-conservative (NO and PO). Then, the estimated mixing patterns were used to reconstruct conservative D_Ba distributions. Comparing these latter to the observed D_Ba provides an objective identification of regions of depletion or enrichment. Finally, the results are discussed in the context of the Mediterranean D_Ba cycling and its potential connections to the carbon dynamics.

\section{Methodology}

The concentration of dissolved barium [D_Ba $\left.{ }^{\text {obs }}\right]$ (or of any other biogeochemical property) of a water sample can be decomposed in a conservative part $\left(\left[\mathrm{D} \_\mathrm{Ba}^{\text {cons }}\right]\right)$ due to the oceanic circulation and a nonconservative part ([D_Ba $\left.\left.{ }^{n c}\right]\right)$, due partly to exchanges with the atmosphere, the rivers or the sediments, and partly to biological activity.

$$
\left[\mathrm{D} \_\mathrm{Ba}^{\mathrm{obs}}\right]=\left[\mathrm{D} \_ \text {Ba }{ }^{\text {cons }}\right]+\left[\mathrm{D} \_\mathrm{Ba}{ }^{\mathrm{nc}}\right]
$$

Therefore, we seek to estimate $\left[\mathrm{D} \_\mathrm{Ba}^{\mathrm{cons}}\right]$ in order to calculate the relative contribution from nonconservative processes. We are particularly interested in investigating how the spatial patterns of [D_Banc] can be related to mesopelagic organic carbon remineralization. Note that we will refer to the nonconservative component $\left(\left[\mathrm{D} \_B a^{\mathrm{nc}}\right]\right)$ as D_Ba anomalies.

\subsection{Parametric Optimum Multiparameter Analysis}

Estimating the contribution of the oceanic circulation to the distribution of D_Ba (or any other tracer) remains a tremendous challenge due to the large range of physical processes coming into play (from basin-scale advection to small-scale isotropic diffusion). A widely used technique consists in approximating a water parcel 
as the result of mixing between several source waters, the so-called Optimum Multiparametric (OMP) analysis [Tomczak, 1981]. OMP analysis is based on the assumption that the properties of the water sample can therefore be approximated as the linear combination of different source water fractions

$$
P=x_{1} P_{1}+x_{2} P_{2}+\ldots+x_{n_{s}} P_{n_{s}}+\varepsilon_{P}
$$

where $x_{i}=x_{1} \ldots x_{n_{s}}$ represent the contribution of the $n_{s}$ source waters (defined by their properties $P=1 \ldots P_{n_{p}}$ ) to the measured property, $P . \varepsilon_{P}$ represents the noise due to the instrumental errors and to the physical assumptions underpinning the OMP model. If $n_{p}$ parameters are measured at N positions, then equation (2) can be written in a matrix form

$$
\mathbf{P}=\mathbf{S} \cdot \mathbf{X}+\mathbf{E}
$$

where $\mathbf{S}_{k}$ is the $\left(n_{p} \times n_{s}\right)$ matrix containing the properties of the source water, $\mathbf{X}$ is the $\left(n_{s} \times N\right)$ matrix containing the unknown fractions, and $\mathbf{P}$ is the $\left(n_{p} \times N\right)$ measurement matrix. Classical OMP technique solves equation (3) for $\mathbf{X}$ containing many unknowns (one for each individual observation). This large number of unknowns is one of the major problems of this approach. Indeed, since all the unknowns are solved independently from each other, the resulting source water fractions lack spatial coherence. More importantly, the large number of unknowns combined to the limited number of available conservative tracers result in a number of statistical imperfections of equation (3). Most notably, it requires that $n_{S}<<n_{P}$ to obtained an overdetermined system, while in practice the number of available parameters is limited to a handful.

Alternatively, we can parameterize the source water fractions as a linear combination of continuous functions defined to follow the geographical setting of the observations [de Brauwere et al., 2007]. Such an approach was developed by de Brauwere et al. [2007], who named it Parametric OMP (POMP). This approach offers some spatial coherence to the source water distribution, whereas the classical OMP solves the individual points independently from its neighbors. POMP is relying on a statistical representation of the source water fractions with no physical link to the data, and therefore, the choice of functions is arbitrary. Hydrographic sections being on a two-dimensional (depth longitude) grid, we use a linear combination of $n_{B}$ two-dimensional spline basis functions $B$, alongside their coefficients $C$, evaluated at the position of the measurement (defined by the horizontal position $\phi$ and depth $z$ ) to model the source water fractions. The two-dimensional functions are defined as

$$
x_{\mathrm{sw}}(\phi, z)=\sum_{b=1}^{n_{B}} c_{\mathrm{sw}, b} B_{b}(\phi, z)
$$

For simplicity, the two-dimensional functions $B$ are formed by combinations of two one-dimensional B-spline functions [de Brauwere et al., 2007]

$$
B_{b}(\phi, z)=N_{i, k_{\phi}}(\phi) M_{j, k_{z}}(z)
$$

where $N_{i, k_{\phi}}(\phi)$ is the $i^{\text {th }}$ (out of $n_{\phi}$ ) B-spline, with an order $k_{\phi}$ in the horizontal direction evaluated in $\phi$, and $M_{j, k_{z}}(z)$ is the $j^{\text {th }}$ (out of $n_{z}$ ) B-spline, with an order $k_{z}$ in the vertical direction evaluated in $z$. Combining equation (4) in a matrix form, we rewrite equation (3) as

$$
\mathbf{Y}=\mathbf{S} \cdot \mathbf{C} \cdot \mathbf{B}^{T}+\mathbf{E}
$$

where $\mathbf{C}$ represents the $\left(n_{S} \times n_{B}\right)$ spline coefficients matrix, $\mathbf{B}$ is a $\left(N \times n_{B}\right)$ basis function matrix. Equation (6) offers the advantage of reducing the number of unknowns $\left(n_{B}<<N\right)$ avoiding the problem of underdetermined systems. On the other hand, the choice of the parameters of the B-basis function is somewhat arbitrary. These B-splines are defined by knots (fixing their number $n_{\phi}$ and $n_{z}$ ) and by an order $\left(k_{\phi}\right.$ and $\left.k_{z}\right)$ that need to be defined. $n_{\phi} n_{z}=n_{B}$ is the total number of basis functions used to parameterize the source water fractions (see de Brauwere et al. [2007] for a complete discussion).

Based on these mixing fractions, we can reconstruct $\left[\mathrm{D} \_\mathrm{Ba}\right]^{\mathrm{cons}}$, the conservative component of $\left[\mathrm{D} \_\mathrm{Ba}\right]^{\text {obs }}$ due to the oceanic circulation:

$$
\left[\mathrm{D} \_\mathrm{Ba}\right]^{\mathrm{cons}}=x_{1}\left[\mathrm{D} \_\mathrm{Ba}\right]_{\mathrm{sW} 1}+x_{2}\left[\mathrm{D} \_\mathrm{Ba}\right]_{\mathrm{sW} 2}+\ldots+x_{n_{s}}\left[\mathrm{D} \_\mathrm{Ba}\right]_{\mathrm{sW}_{n} s}
$$




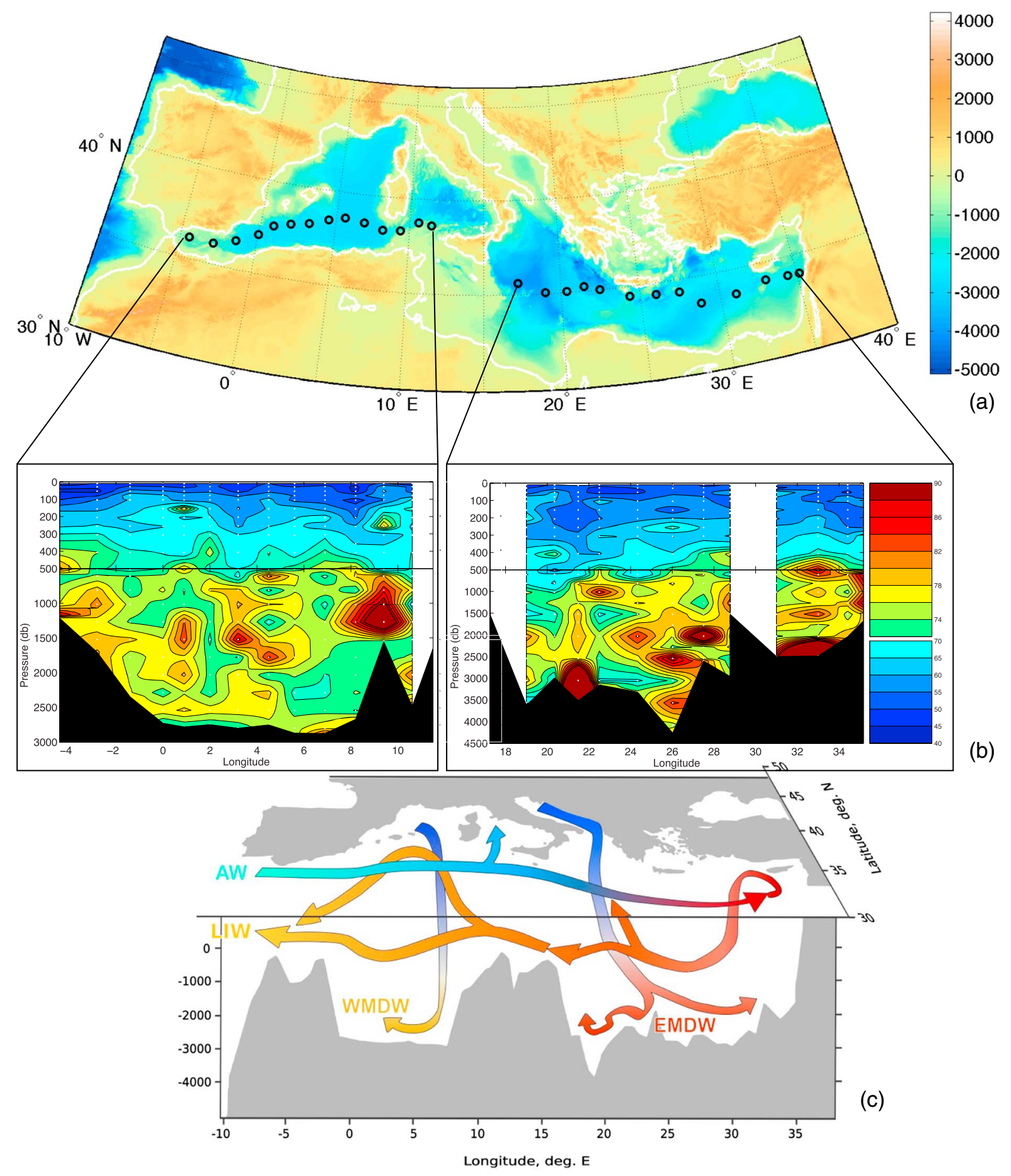

Figure 1. (a) Positions of the M84/3 stations used to perform the POMP analysis superposed on top of the Mediterranean bathymetry (in meters, Source: GEBCO_08 Grid version 20091120, available at http://www.gebco.net). (b) Sections of D_Ba distribution (nmol kg-1) in the Mediterranean Sea from the Meteor cruise M84/3. (c) Schematic of the Mediterranean Overturning Circulation (adapted from Tsimplis et al. [2006]). Colors highlight the change in salinity associated with the overturning circulation (blue = low salinity and red = high salinity). Water masses are defined as follows: AW: Atlantic Water, LIW: Levantine Intermediate Water, WMDW: Western Mediterranean Deep Water, EMDW: Eastern Mediterranean Deep Water. (Courtesy of Loic Houpert).

\section{Data}

The M84/3 cruise, which took place in April 2011 (R/V Meteor) [Tanhua et al., 2013a], occupied a quazi-zonal transect from Istanbul to Vigo as well as northward extension in the Ionian Basin up to the Otranto Strait. Here we focus on the zonal transect (Figure 1a). 


\subsection{Dissolved Barium}

D_Ba data from the M84/3 cruise are discussed in Jacquet et al. [2016]. Briefly, results showed that over the basin the D_Ba content ranges from 38 to $85 \mathrm{nmol} \mathrm{kg}^{-1}$ with local deep D_Ba maxima reaching up to $172 \mathrm{nmol} \mathrm{kg}^{-1}$ (Figure 1b). Deep D_Ba maxima are associated with near bottom waters influenced by benthic processes and brine waters. The water column is largely undersaturated with respect to barite with water column barite saturation state ranging between 0.2 and 0.6 over the basin. D_Ba data are available in the Carbon Dioxide Information Analysis center data repository, next to other physical and chemical parameters obtained during the M84/3 cruise (http://cdiac.ornl.gov/oceans/Coastal/Meteor_Med_Sea.html).

\subsection{Hydrographic Setting}

A detailed description of the hydrography of the M84/3 cruise is given in Tanhua et al. [2013b] and Hainbucher et al. [2013]. Here we provide a brief overview of the main features of importance for the study. The Mediterranean Sea is a three-layer system (Figure 1C). Warm and fresh Atlantic Water (AW) enters through the Strait of Gibraltar, becoming progressively saltier as it circulates around the Mediterranean Basin until it becomes Levantine Surface Water (LSW) in the easternmost corner of the Mediterranean Sea. There, the salty surface water subducts to the subsurface to form Levantine Intermediate Water (LIW), which returns westward toward Gibraltar. In both the western and eastern Mediterranean basins, the surface and intermediate waters act as precursors for the formation of bottom water via deep convection under intense winter time air-sea heat loss. A noteworthy difference in the formation of bottom water in both basins lies in the sites of formation. In the eastern basin, the eastern Mediterranean Deep Water (EMDW) is formed in adjacent seas (the Adriatic and Aegean Seas), while in the western basin, the formation of western Mediterranean Deep Water (WMDW) predominantly occurs in the main basin, in the Gulf of Lion. Both water masses have undergone drastic, transient changes in their thermohaline properties. The eastern Mediterranean transient (EMT), characterized by a displacement of the predominant source of EMDW from the Adriatic Deep Water (AdDW) entering the eastern Mediterranean Sea through the Otranto Strait to Cretan Deep Water (CDW) formed in the Aegean Sea in $1991-1992$, led to a significant renewal of the deep waters [Roether et al., 2007]. In the late 1990s, the Adriatic source became again the dominant source of EMDW, leading to gradual reversal to pre-EMT conditions [Roether et al., 2007; Schneider et al., 2014]. In the western Basin, an intense episode of deep water formation in the mid-2000s led to the formation of warmer and saltier WMDW and was named western Mediterranean transient (WMT) [Schroeder et al., 2008, 2010].

\subsection{Parameter Choice for POMP}

The CTD and bottle data collected during the cruise are used to decide which properties will be used for the POMP analysis and to estimate the source water values for each property. Note that Hainbucher et al. [2013] previously performed an OMP analysis of this data set. A simple approach would have been to use the fractions calculated by Hainbucher et al. [2013] to estimate [D_Ba ${ }^{\text {cons }}$ ]. However, this is not possible mainly because Hainbucher et al. [2013] used several OMP analyses in order to reconstruct different water masses independently. The consequence of this approach is the absence of conservation of the reconstructed water masses (i.e., for a given observation, the sum of the fractions presented in their study is not equal to 1). This poses a major issue for the present work, which strives to assess the degree of conservativity of D_Ba and therefore requires that the reconstruction of the water masses is equal to 1 .

To perform the mixing fraction analysis used to reconstruct $\left[\mathrm{D} \_\mathrm{Ba}\right]^{\text {cons }}$, we tested four different conservative (potential temperature $\Theta$ and salinity) and quasi-conservative $\mathrm{NO}, \mathrm{PO}$ variables. $\mathrm{NO}\left(\mathrm{NO}=9 \mathrm{NO}_{3}+\mathrm{O}_{2}\right)$ and $\mathrm{PO}\left(\mathrm{PO}=170 \mathrm{PO}_{4}+\mathrm{O}_{2}\right)$ are tracers based on phosphate and nitrate corrected for respiration [Broecker, 1974]. We use the classical Redfield ratios in agreement with the Mediterranean literature [Moutin and Raimbault, 2002; Pujo-Pay et al., 2011; Tanhua et al., 2013a]. NO and PO are not completely independent from one another (since both require corrections for respiration from oxygen). Therefore, several sensitivity tests were performed in order to choose the optimum combination of parameters resulting in water mass fraction distribution consistent with our current knowledge of the Mediterranean water mass structure. Finally, the parameters of equation (6) are weighted using the standard deviation of the observations to reflect our confidence in the source water property definition. This weighting scheme provides more weight to potential temperature and salinity than to NO and PO.

To define the properties of the source waters, we analyzed potential temperature $(\Theta)$-salinity (Figure 2), NO-S, PO-S diagrams observed during the M84/3 cruise. While many water masses have been identified in the Mediterranean Sea [Millot and Taupier-Letage, 2005], their thermohaline property range is relatively narrow, thus limiting the possibility of using many of these water masses as end-members for the POMP analysis. 

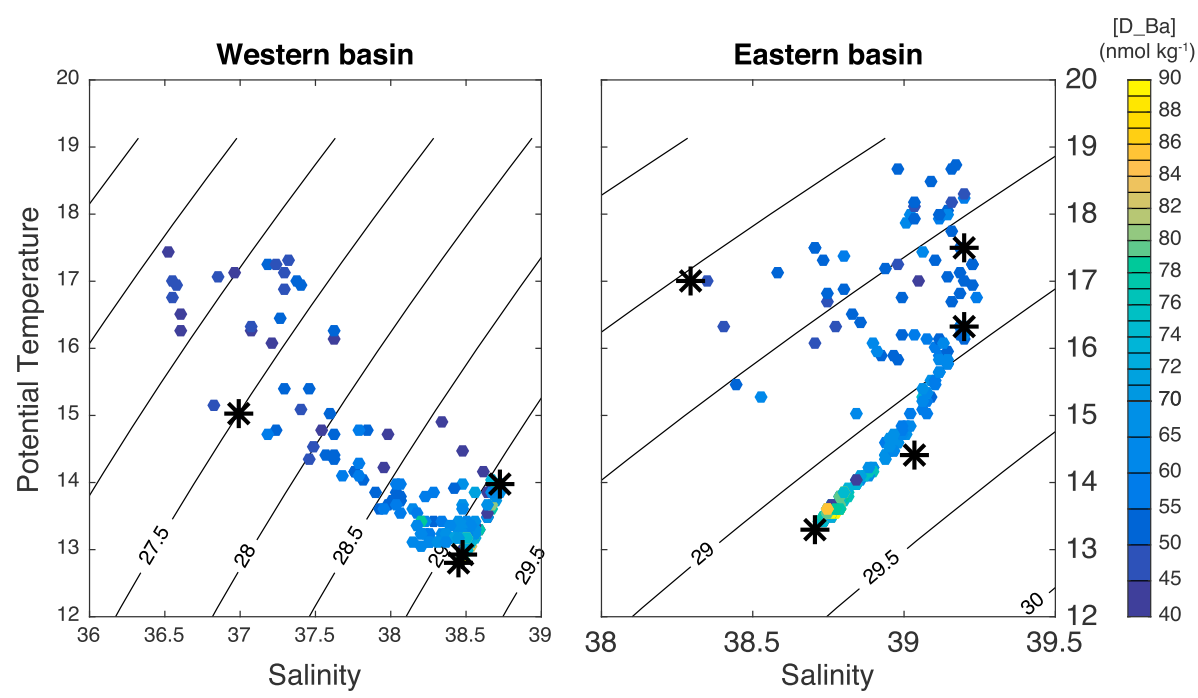

Figure 2. D_Ba distribution in potential temperature $(\Theta)$-salinity coordinates for the (left) western and (right) eastern Mediterranean basins. The black stars represent the $\Theta-S$ properties for the different source waters (Tables 1 and 2 ).

Therefore, for this study, we only consider the main water masses described above (Tables 1 and 2). Note that the mean temperature and salinity values for the surface waters are taken below the surface mixed layer in order to minimize the seasonal variability affecting the mixed layer. This results in the presence of data outside of the end-members field (Figure 2).

In the western basin, the four end-member POMP analyses $(\Theta, S, N O$, and $P O)$ offer the most satisfactory reconstruction of the hydrography, particularly in the deep layers in the transition region between the post-WMT and pre-WMT water masses (Figure S1 in the supporting information). In the eastern basin, however, the results from the four end-member POMP analyses strongly resemble those from $\Theta-S-P O$ run, while the $\Theta$-S-NO run is markedly different. An analysis of the residual for the individual properties used for the POMP analysis reveals that the model is unable to reconstruct the NO field (the residual, data-reconstructed fields are consistently biased toward negative values meaning that the modeled values are higher than the observations; Figure S2). The reason for this lack of reconstruction remains unclear. Sensitivity analysis in which the NO values for the different source waters have been adjusted did not change the results significantly. Therefore, we conclude that in the eastern basin the $\Theta-S-P O$ POMP analysis provides the most accurate description of the local hydrography.

In order to reconstruct [D_Ba $]^{\text {cons }}$ using equation (7), we define the D_Ba concentration of the different source waters by identifying the D_Ba values corresponding to the salinity and potential temperature definitions of the source waters (Tables 1 and 2). Considering the sampling uncertainty of D_Ba (around $1 \mathrm{nmol} \mathrm{kg}^{-1}$ ), we round our D_Ba values for the source waters to the nearest integer.

\subsection{Uncertainty Calculation}

Despite the statistical improvement over the classical OMP methodology, the POMP approach still suffers from several limitations (choice of the parameters used for the model, source water definitions, and measurement variability) whose impact on the determination of the water mass fractions and the subsequent reconstructed

Table 1. Definition of the Water Mass Properties Used as Input Parameters for the POMP Model in the Western Basin of the Mediterranean Sea

\begin{tabular}{lccccc} 
& $\begin{array}{c}\Theta \\
\left({ }^{\circ} \mathrm{C}\right)\end{array}$ & $\mathrm{S}$ & $\begin{array}{c}\text { NO } \\
\left(\mu \mathrm{Mol} \mathrm{kg}^{-1}\right)\end{array}$ & $\begin{array}{c}\text { PO } \\
\left(\mu \mathrm{Mol} \mathrm{kg}^{-1}\right)\end{array}$ & $\begin{array}{c}\text { D_Ba } \\
\left(\mathrm{nmol} \mathrm{kg}^{-1}\right)\end{array}$ \\
\hline AW & 15.00 & 37.000 & 246 & 252 & 50 \\
LIW & 14.00 & 38.726 & 234 & 229 & 60 \\
Post-WMT WMDW & 12.9 & 38.485 & 270 & 261 & 80 \\
Pre-WMT WMDW & 12.8 & 38.462 & 280 & 270 & 83 \\
\hline
\end{tabular}


Table 2. Definition of the Water Mass Properties Used as Input Parameters for the POMP Model in the Eastern Basin of the Mediterranean Sea

\begin{tabular}{|c|c|c|c|c|}
\hline & $\begin{array}{c}\Theta \\
\left({ }^{\circ} \mathrm{C}\right) \\
\end{array}$ & $\mathrm{S}$ & $\begin{array}{c}\mathrm{PO} \\
\left(\mu \mathrm{Mol} \mathrm{kg}^{-1}\right) \\
\end{array}$ & $\begin{array}{c}\text { D_Ba } \\
\left(\mathrm{nmol} \mathrm{kg}^{-1}\right)\end{array}$ \\
\hline AW & 17.00 & 38.300 & 240 & 40 \\
\hline LSW & 17.50 & 39.200 & 221 & 56 \\
\hline AdDW & 13.30 & 38.700 & 239 & 80 \\
\hline CDW & 14.43 & 39.040 & 225 & 75 \\
\hline
\end{tabular}

D_Ba field ([D_Ba $\left.{ }^{\text {cons }}\right]$, equation (7)) need to be carefully estimated. In order to assess this sensitivity, we use an empirical approach similar to a Monte Carlo experiment. First, we test the sensitivity of the results to variability in the observations by generating 1000 sets of $\Theta, S, N O$, and PO. These data sets are created so that for each property, the distribution of 1000 sets is Gaussian, centered around the mean value of our observations, and with a standard deviation equal to the observed standard deviation. The noise introduced in the data is larger than the instrumental error for each parameter. Second, we test the impact of the uncertainties on the source water definition by randomly generating 1000 sets of source waters used as input for the POMP (Figure S3). These source water definitions reflect observed variability that is greater near the surface than in the deep ocean [see, e.g., Schroeder et al., 2013]. The uncertainties are then defined as the standard deviations of these 2000 runs.

\section{Results}

\subsection{Source Waters Fraction}

We briefly describe the contribution of the different source waters to the water mass distribution during the M84/3 cruise as well as the associated residuals in order to verify that our water mass distribution is coherent with our current understanding of the Mediterranean circulation.
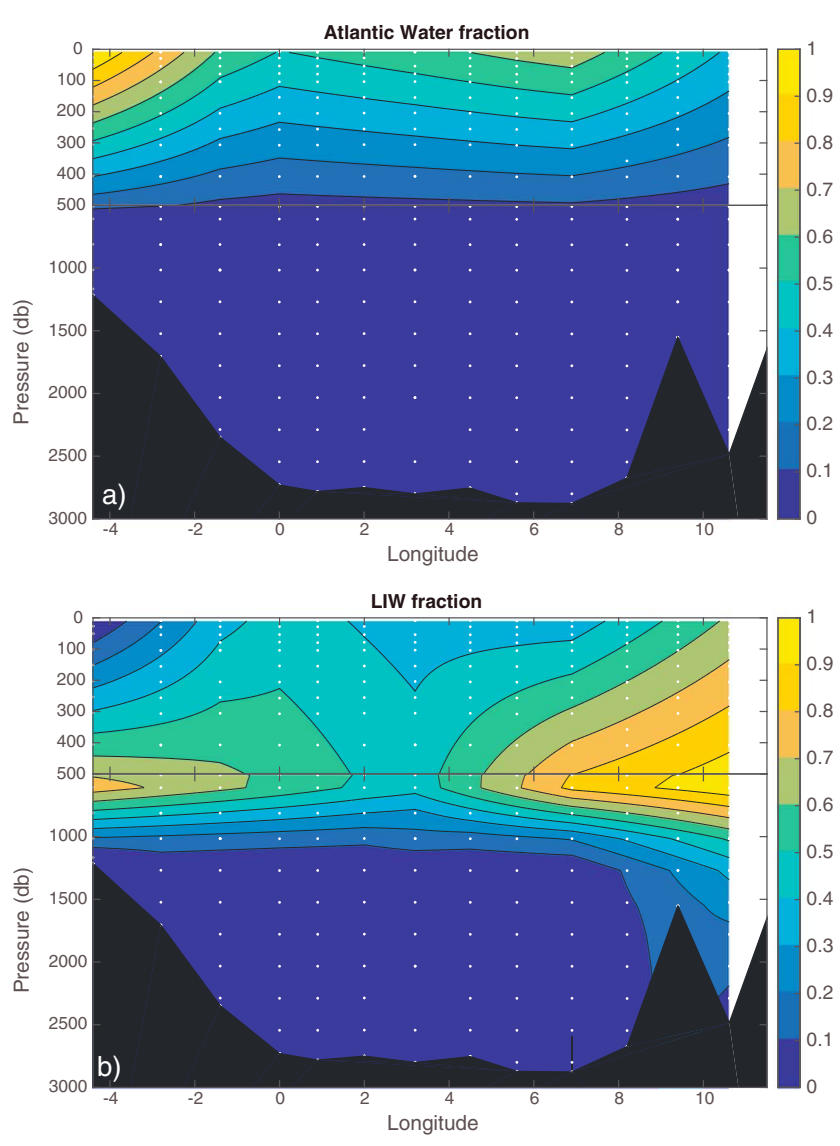
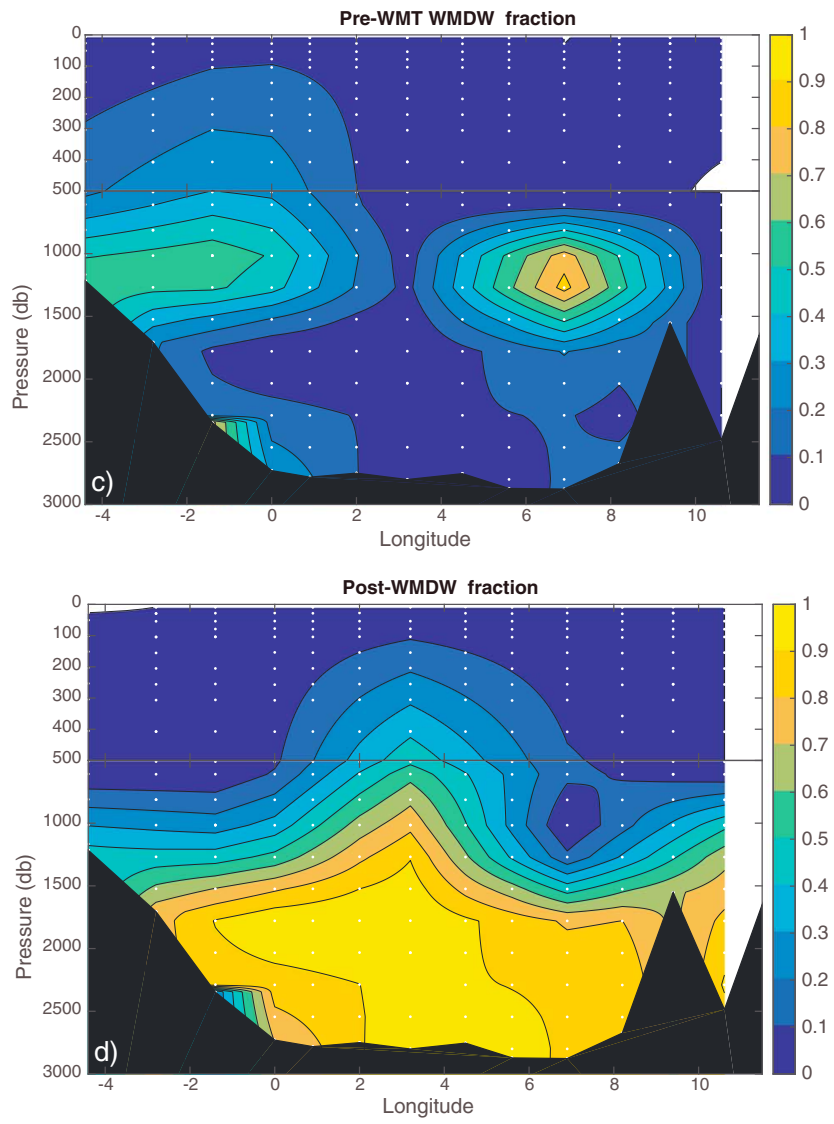

Figure 3. Sections of the fraction for the different source waters in the western Mediterranean basin. (a) Atlantic Water, (b) Levantine Intermediate Water, (c) Pre-WMT western Mediterranean Deep Water, (d) Post-WMT western Mediterranean Deep Water. 

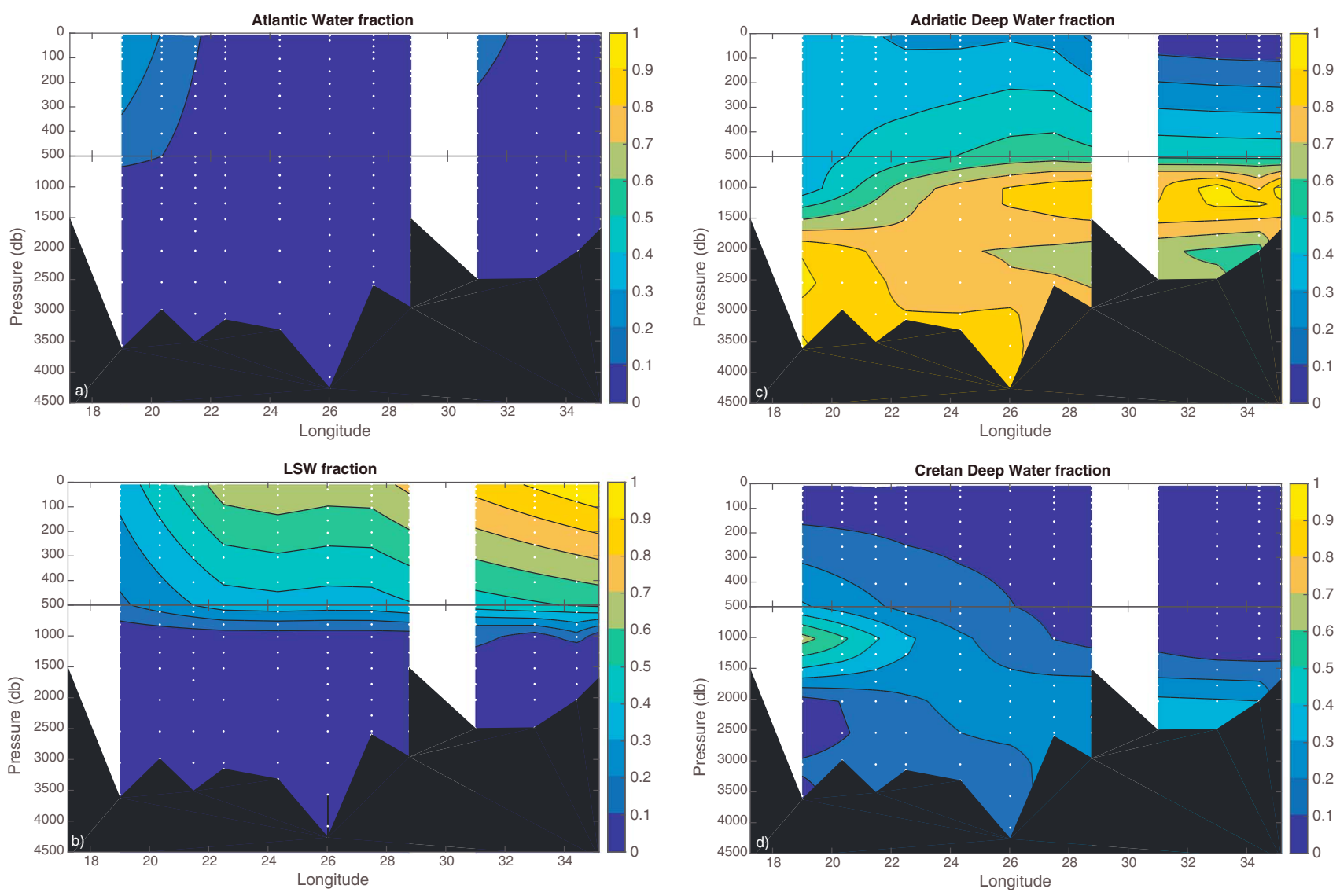

Figure 4. Sections of the fraction for the different source waters in the eastern Mediterranean basin. (a) Atlantic Water, (b) Levantine Surface Water, (c) Adriatic Deep Water, (d) Cretan Deep Water.

In the western basin (Figure 3), AW dominates the upper $300 \mathrm{~m}$, while the 300 to $1000 \mathrm{~m}$ range is mostly occupied by the salty LIW. The deep basin is mostly occupied by the WMDW. The post-WMT bottom water is the most abundant water mass, and the pre-WMT bottom water is only present in the 1000-1500 m depth range. In the eastern basin, the upper $500 \mathrm{~m}$ is dominated by the LSW with only a minor contribution from AW in the lonian basin (Figure 4). Below $500 \mathrm{~m}$, AdDW is the dominant water mass, while CDW only contributes to the water mass distribution in the 500-1500 m depth range of the lonian basin. In both basins, the residuals for each parameter (E in equation (6) are small and approximately normally distributed around 0 (Figures 5 and 6), even though the distribution of the $\Theta(S)$ residuals is slightly skewed toward negative (positive) values in the western basin. The vertical distribution of the residuals shows a maximum in the upper water column suggesting that the model is less able to reconstruct the subsurface water masses where variability is stronger.

Nevertheless, our results agree qualitatively with the fractions obtained by Hainbucher et al. [2013] reinforcing the validity of our model choices. Overall, the mixing fractions obtained from the POMP analysis provide a first-order description of the large-scale water mass distribution in the Mediterranean Sea allowing to obtain a reliable estimate of the $\left[\mathrm{D} \_B \mathrm{~B}^{\text {cons }}\right]$.

\subsection{Water Mass Uncertainties and Impact on the D_Ba Distribution}

We estimate the mean uncertainties in the mixing fractions to be 5, 19, 22, and 19\% for AW, LIW, post-WMT WMDW, and pre-WMT WMDN, respectively, in the western basin and 8, 10, 15, and 12\% for AW, LSW, CDW, and AdDW, respectively, in the eastern basin. The larger uncertainties of the western basin are most likely caused by the similarity of the properties of the two bottom water types (Tables 1 and 2 and Figure 2), making the POMP analysis more sensitive to small variations in the data or the source water definitions. Overall, this sensitivity analysis demonstrates that POMP analysis is a valuable tool to decompose the contribution of biogeochemical processes from the background oceanic circulation despite the physical limitations of the POMP model. 

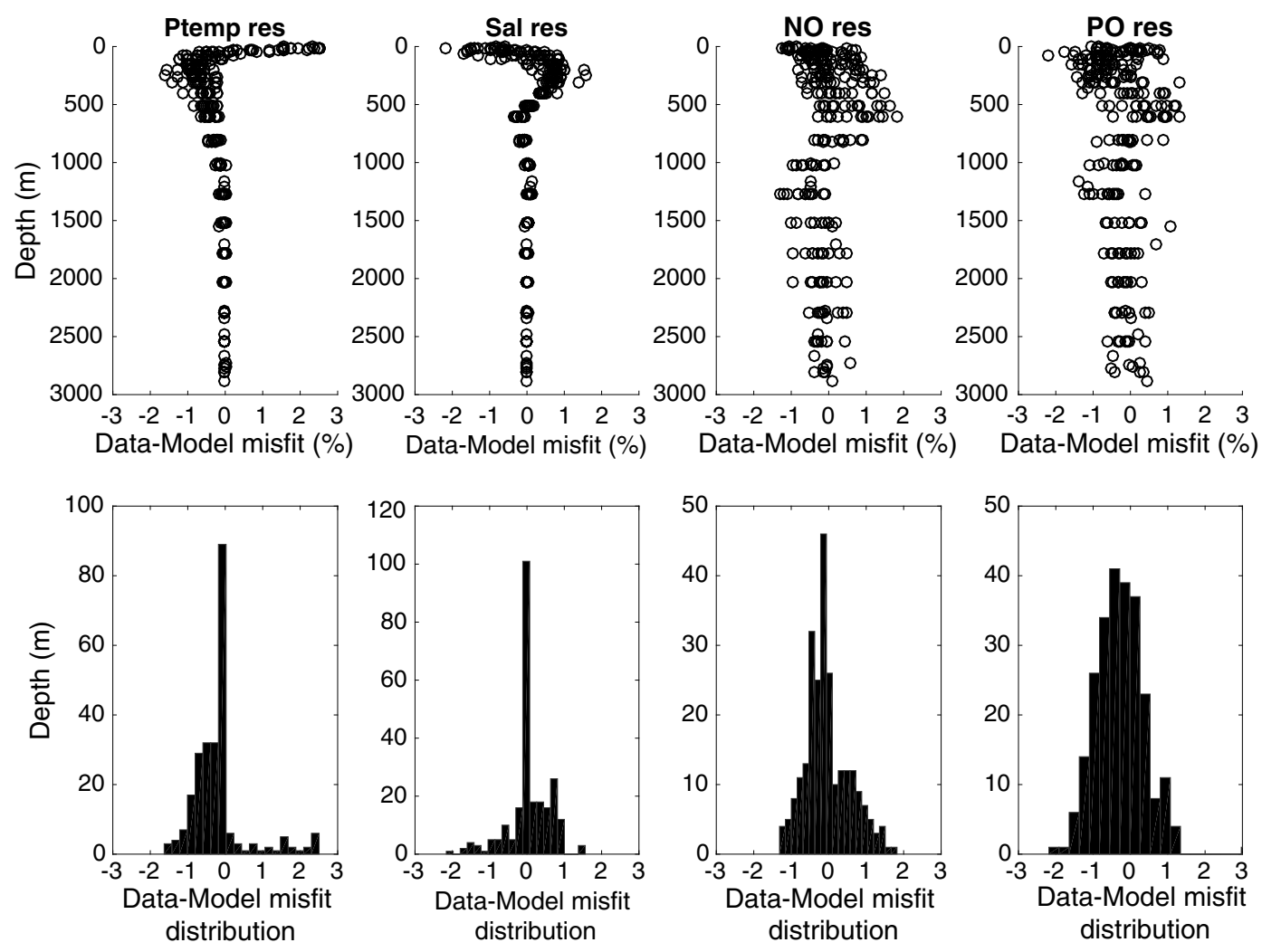

Figure 5. Sections of the fraction for the different source waters in the western Mediterranean basin: Atlantic Water, Levantine Intermediate Water, Pre-WMT western Mediterranean Deep Water, and Post-WMT western Mediterranean Deep Water.

The spatial distribution of the standard deviation of the reconstructed D_Ba field, based on the two sets of Monte Carlo simulations, is shown in the supporting information (Figure S4). Adding noise to the data results in larger uncertainties in the D_Ba distribution (up to $5 \mathrm{nmol} \mathrm{kg}^{-1}$ ), while uncertainties in the source water definition result in standard deviation less than $3 \mathrm{nmol} \mathrm{kg}^{-1}$. Therefore, the D_Ba anomalies calculated with the POMP analysis are relatively robust to uncertainties in the data as well as the source water definition.

4.3. [D_Banc]

Based on equation (1), we can estimate the [D_Ban ${ }^{\text {nc }}$ by subtracting the reconstructed D_Ba field (Figure S5) from the observations. We assess the robustness of these anomalies by constructing $2000\left[D_{-} B a^{\text {cons }}\right]$ fields based on the water mass fractions obtained from the Monte Carlo approach described above. We find that $97 \%$ of the $\left[\mathrm{D} \_\mathrm{Ba}^{\text {cons }}\right]$ samples have a standard deviation less than $5 \mathrm{nmol} \mathrm{kg}{ }^{-1}$. This suggests that values of $\left[\mathrm{D} \_B a^{\mathrm{nc}}\right]$ less than $5 \mathrm{nmol} \mathrm{kg}{ }^{-1}$ are not statistically different from the noise caused by assumptions in the POMP model and measurement uncertainties. Only seven samples with uncertainties larger than $5 \mathrm{nmol} \mathrm{kg}^{-1}$ have been removed suggesting that the uncertainties in the water mass fractions only minimally impact the D_Ba anomalies.

Several localized anomalies clearly stand out (Figure 7a). In the western basin two major positive anomalies are located near $9.5^{\circ} \mathrm{E}$ and $4^{\circ} \mathrm{W}$. They range from 7 to $20 \mathrm{nmol} \mathrm{kg}{ }^{-1}$, peaking at $20 \pm 3 \mathrm{nmol} \mathrm{kg}{ }^{-1}$ near $9.5^{\circ} \mathrm{E}$. These anomalies (red patches) are associated with topographic obstacles, a sea mount, and the entrance of the Gibraltar Strait. A similar positive anomaly of matching amplitude is also found in the Levantine basin (east of $30^{\circ}$ ) centered around $500 \mathrm{~m}$ (maximum at $19 \pm 2 \mathrm{nmol} \mathrm{kg}^{-1}$ ). The positive anomalies deviate by 5 to $20 \%$ from the mixing-only scenario (Figure $7 \mathrm{~b}$ ). They reflect an enrichment of D_Ba in the observations compared with the reconstructed D_Ba and hint at a dissolution of Ba-rich particles at these depths.

D_Ba-depleted regions (deviation by 5 to $20 \%$ from the physics-only scenario; Figure $7 \mathrm{~b}$ ), characterized by negative $\left[\mathrm{D} \_\mathrm{Ba}{ }^{\mathrm{nc}}\right]$ (blue patches) extend over larger areas than the enriched regions. In the western basin, the upper $150 \mathrm{~m}$ of the water column over the entire section is depleted in D_Ba (a minimum at $-19 \pm 4 \mathrm{nmol} \mathrm{kg}^{-1}$ ), 

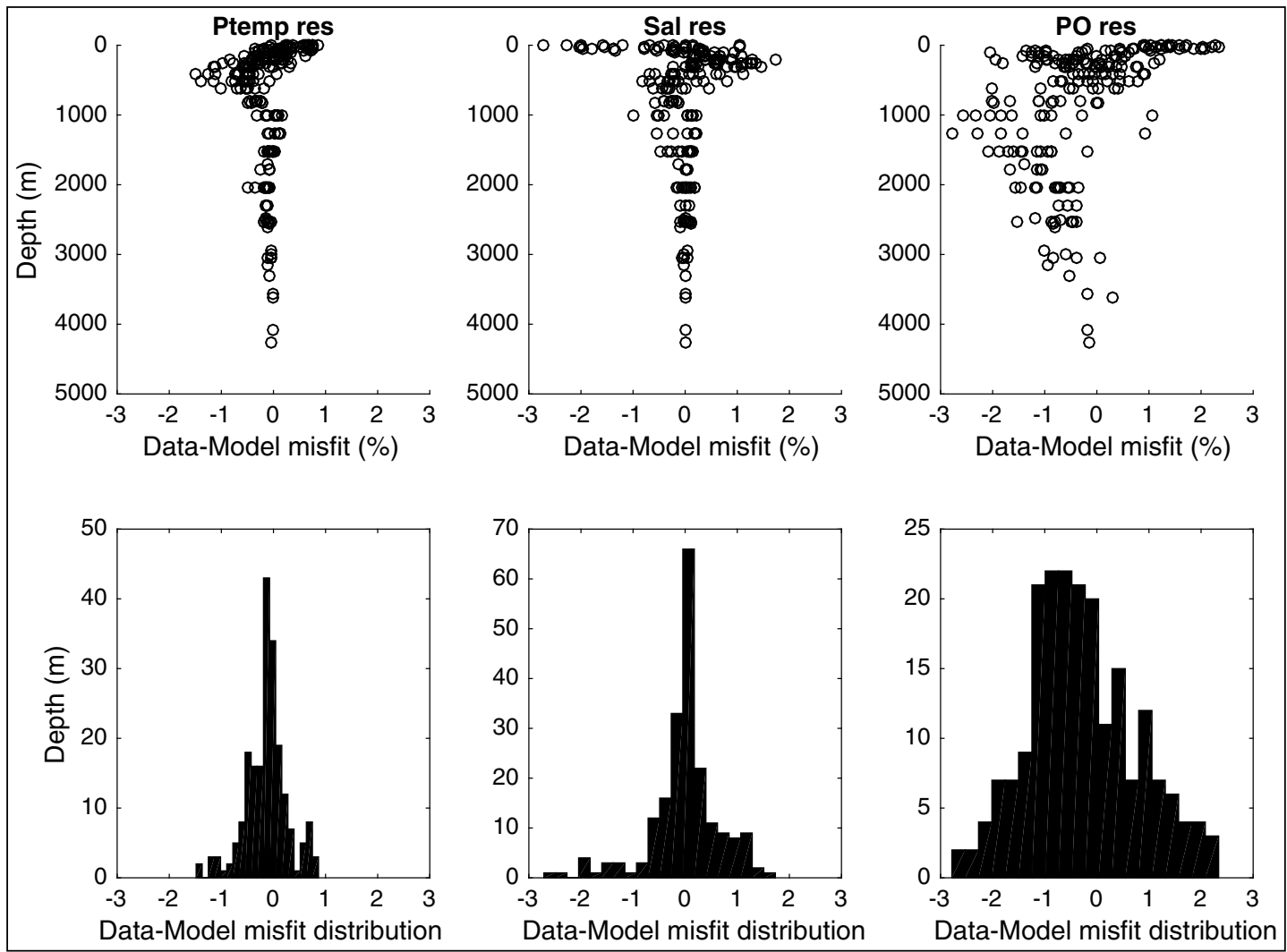

Figure 6. Sections of the fraction for the different source waters in the eastern Mediterranean basin: Atlantic Water, Levantine Surface Water, Adriatic Deep Water, and Cretan Deep Water.

while in the eastern basin, the mesopelagic depletion extends deeper (down to $400 \mathrm{~m}$ ) between $19^{\circ}$ and $31^{\circ} \mathrm{E}$ (minimum $=-17 \pm 3 \mathrm{nmol} \mathrm{kg}^{-1}$ ) even though a gap in the data set prevents us from identifying the eastern extent of this depletion zone with precision. Interestingly, the eastern Levantine basin does not seem to host any depletion region. Another striking difference between the western and eastern basins is the presence of a secondary depletion zone located in the deeper part (>1000 m) of the western basin. This depletion peaks at $-9 \pm 4 \mathrm{nmol} \mathrm{kg}^{-1}$. The decrease in D_Ba in the observations compared with the reconstructed field points toward a potential phase transfer from D_Ba to $P \_B a$ barite.

Our results have revealed that despite the presence zones of negligible anomalies $\left(-5<\left[D \_B a n c\right]<5 \mathrm{nmol} \mathrm{kg}^{-1}\right.$ - white patches), significant departures from the background D_Ba distribution still exist. This suggests a nonnegligible contribution from nonphysical processes thus offering a unique window to better understand the biogeochemical cycling of dissolved barium in the Mediterranean Sea as discussed in the following section.

\section{Discussion}

\section{1. [D_Ba $\left.{ }^{\text {cons }}\right]$ Versus [D_Banc]: A Tale of Two (Temporal) Scales}

Equation (1), rather than separating the impact of the overturning circulation from the one of biogeochemical processes, highlights processes occurring on short time scales (a few months) from the background processes reflecting the balance between the overturning circulation and biogeochemical processes. The increase of D_Ba concentration due to $\mathrm{P} \_$Ba barite dissolution in the western Mediterranean Sea was roughly estimated to be less than $1.5 \mathrm{nmol} \mathrm{kg}{ }^{-1}$ by Dehairs et al. [1987]. The lower limits of the D_Ba anomalies reported here are 3 times larger than this value implying that this background dissolution rate is filtered out of the reported anomalies. Therefore, the regions of negligible anomalies (white patches in Figure 7) are not subject to any additional sources or sinks acting on shorter time scales (relative to the overturning circulation $-\sim 50$ years) apart from the background dissolution rate which is integrated by the overturning circulation over longer 

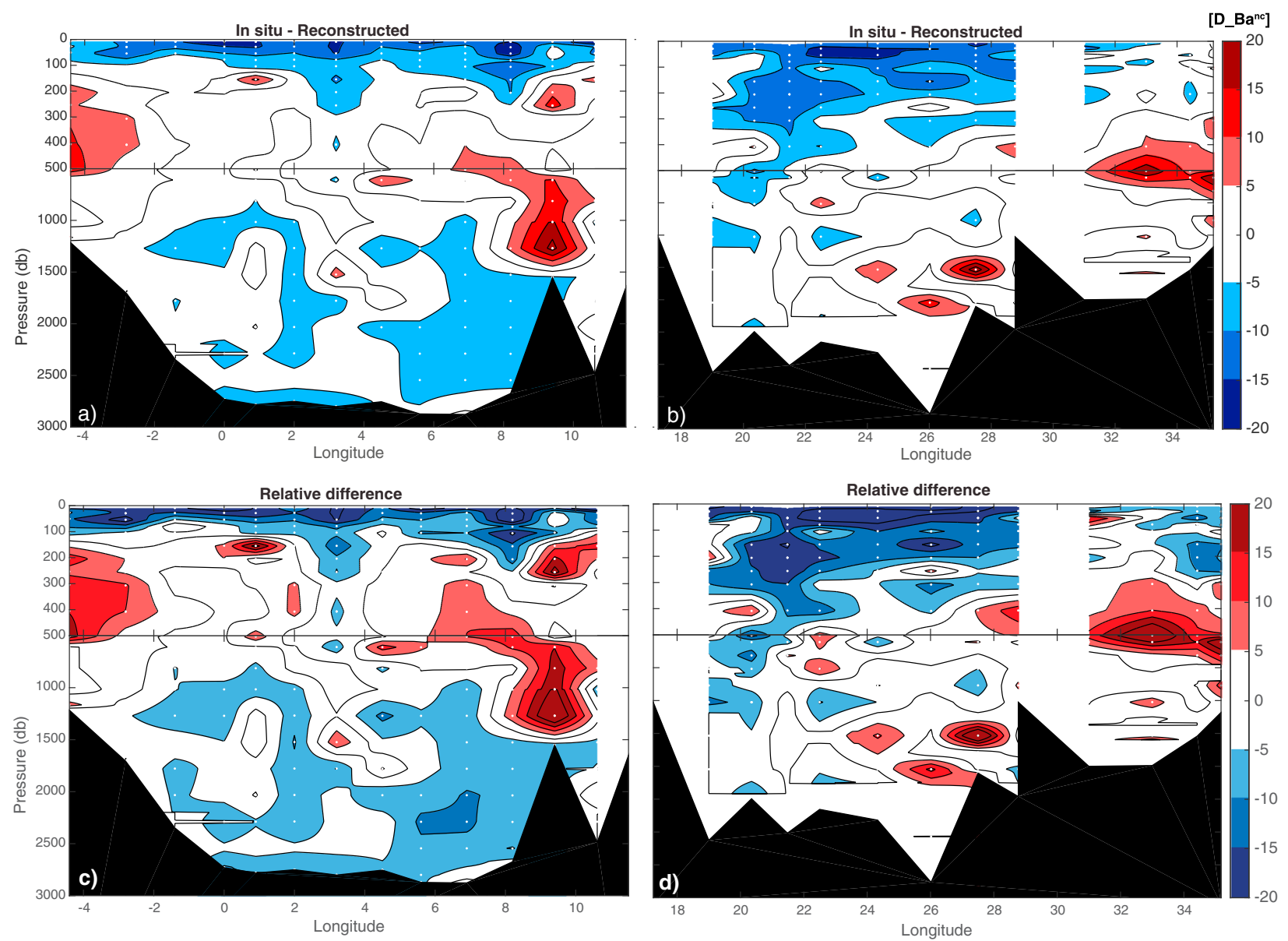

Figure 7. Sections of the $\mathrm{D} \_\mathrm{Ba}$ anomalies $\left(\mathrm{D} \_B a^{\mathrm{nc}}=\right.$ in situ observations-reconstructed field) for the (a) western and (b) eastern Mediterranean basins. Positive and negative values indicate an excess or deficit greater than $5 \mathrm{nmol} \mathrm{kg}{ }^{-1}$ of $D_{-}$Ba in the in situ data compared with the reconstructed field. (c, d) $D \_B a$ relative anomalies (deviation from the mixing-only scenario) $=$ (observation - reconstructed) $\times 100 /$ reconstructed.

time scales. This results in the accumulation of $D_{-}$Ba in the deep ocean characterized by the vertical $D_{-} B a$ gradient (Figure 1b).

Local patches of positive anomalies reflect additional D_Ba fluxes potentially due to the dissolution of Ba-rich material. The location of these anomalies in the western basin appears to be associated with topography (a seamount near $9.5^{\circ} \mathrm{E}$ and the entrance of the Gibraltar Strait). This points to the role of epibenthic D_Ba fluxes potentially driven by dissolution of $P_{-}$Ba barite from resuspension of material exported to depth and accumulated on the seafloor. Strong currents usually associated with these topographical features may potentially cause this resuspension even though the lack of direct measurements prevents us from further conclusions. The positive anomaly centered around $500 \mathrm{~m}$ in the easternmost sector of the Levantine Basin is most likely associated with the presence of an anticyclonic gyre interacting with the Cyprian Plateau, again leading $\mathrm{P}_{-} \mathrm{Ba}$ barite dissolution due to resuspension of accumulated material or to Ba-rich material erosion. This result suggests that the intermediate waters of the Levantine Basin are directly influenced by the exchange processes between the continental plateau and the open ocean. This process is commonly referred to as boundary exchange in the literature [Lacan and Jeandel, 2005].

The depletion areas reflect the subtraction of D_Ba from the water column potentially linked to organic carbon remineralization. The upper mesopelagic depletion horizon observed over most of the sections would indicate that regeneration of organic material occurs at these depths as commonly observed in most oceanic basins [Dehairs et al., 1997, 2008; Jacquet et al., 2007b, 2011, 2015]. On the contrary, the absence of significant D_Ba depletion in the ultraoligotrophic easternmost part of the eastern basin [Pujo-Pay et al., 2011; Tanhua et al., 2013a] is due to a combination of relatively low primary production and of the ventilation of intermediate waters resulting in relatively young water masses, which did not have time to accumulate organic matter 


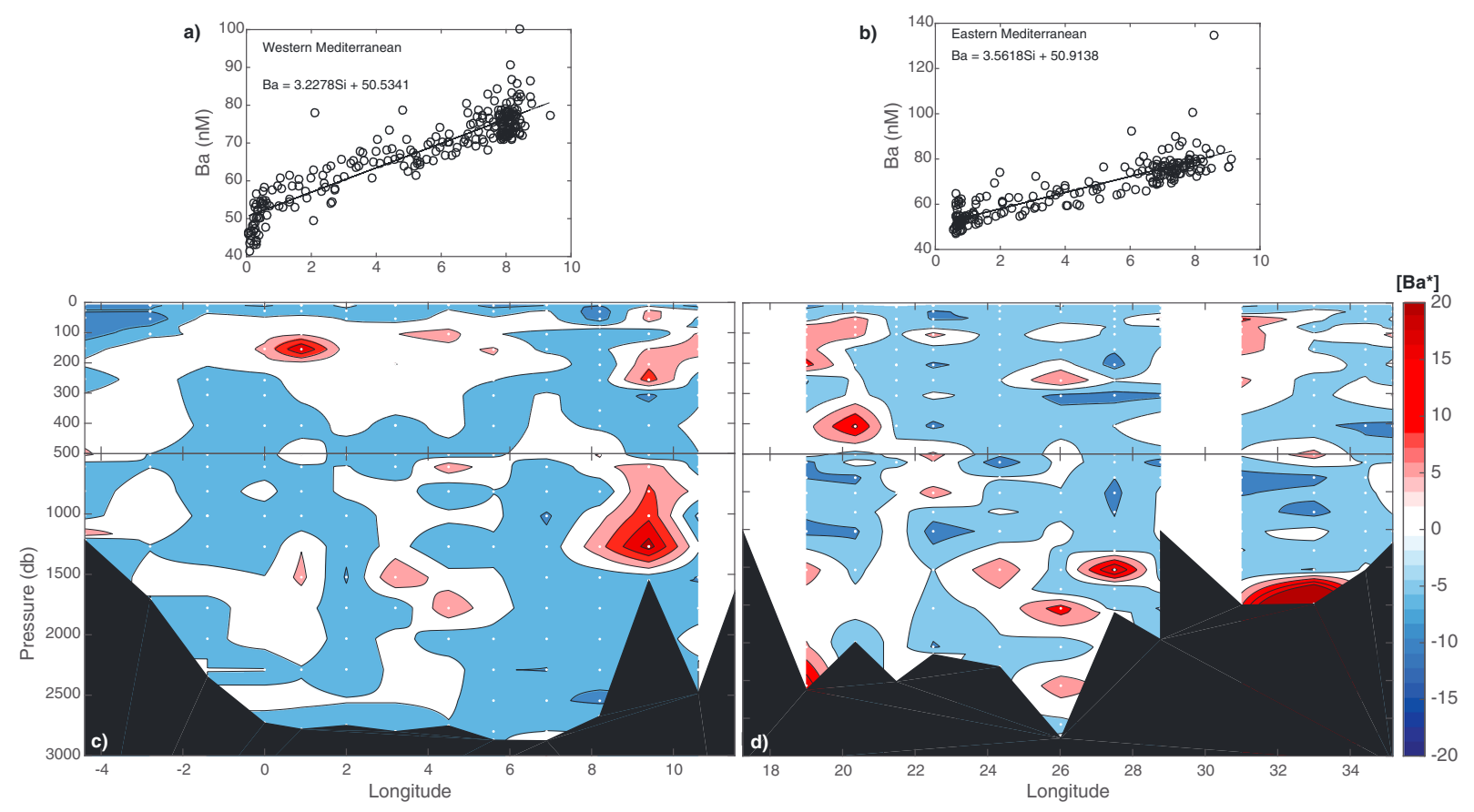

Figure 8. (a, b) D_Ba-Si diagram in the western and eastern basins, respectively. The equations for linear regression line plotted in both panels are shown in the top left corner. (c, d) Ba* (as defined by Horner et al. [2015]) distribution in the western and eastern basins.

degradation. The presence of remineralization horizons below the mesopelagic depth of the western basin is somewhat surprising, but the sensitivity tests show that this is a robust feature of the basin. The winter deep convection events [see, e.g.,Schroeder et al., 2010] can potentially explain this feature by transporting particulate and labile material toward the deep sea thus sustaining prokaryotic activity and remineralization [Tanhua et al., 2013a].

In the global ocean, studies have reported a spatial coherence of $\mathrm{Ba}$ and silicates distribution indicating similar behavior of their dissolved-particulate interactions [Jacquet et al., 2005, 2007a]. Based on these observations, Horner et al. [2015] calculated in the Atlantic Ocean the Ba* tracer using Ba and Si following a similar approach to that Gruber and Sarmiento [1997] did for N*. Ba* reflects the relative deviation from perfect Ba-Si coupling. $\mathrm{Ba}^{*}$ is invariant as long as the uptake/subtraction and regeneration ratio of $\mathrm{Ba}$ and $\mathrm{Si}$ remains constant during biogeochemical cycling. We perform the same calculation in the Mediterranean Sea by calculating the linear regression to the Ba-Si relationship (Figures $8 \mathrm{a}$ and $8 \mathrm{~b}$ ) and then removing this trend from the Ba observations (Figures $8 \mathrm{c}$ and $8 \mathrm{~d}$ ). Positive Ba* can be interpreted as $\mathrm{P}_{-} \mathrm{Ba}$ barite dissolution or silicate precipitation while negative $\mathrm{Ba}^{*}$ reflect the $\mathrm{P}_{-} \mathrm{Ba}$ precipitation or $\mathrm{Si}$ dissolution. The distribution of $\mathrm{Ba}^{*}$ qualitatively agrees with $\mathrm{D}_{-} \mathrm{Ba}^{\mathrm{nc}}$, reflecting the different horizons of dissolution and precipitation described above (Figure 7). The similarity is particularly salient in the western basin. Over the whole Mediterranean Sea negative Ba* exceeds $D_{-} B a^{n c}$. This is potentially due to the fact that $\mathrm{Si}$ dissolution also occurs during $\mathrm{P} \_\mathrm{Ba}$ formation. This is particularly visible in the deep waters in the eastern basin. Ba* positive values reported the entrance of the Gibraltar Strait and in the easternmost sector of the Levantine Basin are less marked than those reported by POMP. This potentially reflects that $\mathrm{Si}$ is also dissolved next to Ba during boundary exchange, thus balancing the net $\mathrm{Ba}^{*}$ estimate. Therefore, $\mathrm{Ba}^{*}$ offers a useful way to describe localized $\mathrm{Ba}$ anomalies with respect to $\mathrm{Si}$, and the good agreement between $\mathrm{Ba}^{*}$ and $\mathrm{Ba}^{\mathrm{nc}}$ reinforces our confidence in the robustness of the results.

\subsection{D_Ba Flux Estimation and Link With Carbon Remineralization}

Based on local D_Ba anomalies, we attempt a loose estimate of the $D \_B a$ enrichment and subtraction fluxes corresponding to the reported magnitude of the $\mathrm{D} \_\mathrm{Ba}^{\mathrm{nc}}$ anomalies. First, we calculate the flux of $\mathrm{D} \_\mathrm{Ba}$ necessary to maintain the positive anomaly over $H$ (the thickness of the water column over which the anomaly extends) based on the mean age of the water mass

$$
D_{-} B a^{\text {flux }}=\frac{\left[\mathrm{D} \_ \text {Ba }{ }^{\mathrm{nc}}\right] H \rho}{\Gamma}
$$


Table 3. D_Ba Enrichment Flux and Parameters Definition for Equation (8)

\begin{tabular}{|c|c|c|c|c|c|c|}
\hline Position & $\begin{array}{l}\mathrm{H} \\
(\mathrm{m})\end{array}$ & $\begin{array}{c}\Gamma \\
\left(\mathrm{yr}^{-1}\right)\end{array}$ & $\begin{array}{c}{\left[\mathrm{D} \_B a^{\mathrm{nc}}\right]^{\text {mean }}} \\
\left(\mathrm{nmol} \mathrm{kg}{ }^{-1}\right)\end{array}$ & $\begin{array}{l}{\left[\mathrm{D} \_\mathrm{Ba}^{\mathrm{nc}}\right]^{\min }} \\
\left(\mathrm{nmol} \mathrm{kg}{ }^{-1}\right)\end{array}$ & $\begin{array}{l}{\left[\mathrm{D} \_\mathrm{Ba}^{\mathrm{nc}}\right]^{\max }} \\
\left(\mathrm{nmol} \mathrm{kg}{ }^{-1}\right)\end{array}$ & $\begin{array}{c}F_{\mathrm{D}_{-} \mathrm{Ba}}^{\min }<F_{\mathrm{D}_{-} \mathrm{Ba}}^{\operatorname{mean}}<F_{\mathrm{D}_{-} \mathrm{Ba}}^{\max } \\
\quad\left(\mu \mathrm{mol} \mathrm{m} \mathrm{m}^{-2} \mathrm{~d}^{-1}\right)\end{array}$ \\
\hline $9.5^{\circ} \mathrm{E}$ & 700 & 200 & 15 & 10 & 20 & $0.1<0.15<0.2$ \\
\hline Gibraltar & 300 & 90 & 10 & 7 & 13 & $0.07<0.09<0.12$ \\
\hline Levantine & 200 & 50 & 12 & 5 & 19 & $0.06<0.13<0.21$ \\
\hline
\end{tabular}

${ }^{a} \mathrm{H}$ is the thickness of the anomaly. $\Gamma$ is the mean age of the water masses based on transient tracer.

$\rho$ is the in situ density, and $\Gamma$ is the mean age of the water mass. We used the water mass age estimated from transient tracers reported in Stöven and Tanhua [2014] (Tables 3 and 4). Keeping in mind the assumptions underpinning equation (8), we bracket our mean estimate of enrichment fluxes by using the minimum and maximum values of the observed anomalies in order to provide upper and lower bounds to our calculation. According to equation (8), we estimate that the $D \_B a$ enrichment flux (from $P \_B a$ dissolution) lies in the range of +0.06 to $+0.21 \mu \mathrm{mol} \mathrm{m} \mathrm{m}^{-2} \mathrm{~d}^{-1}$ (Table 3).

Using equation (8), we also estimate the D_Ba depletion fluxes corresponding to the mesopelagic and deep anomalies (Table 4). They range from -0.07 to $-1.28 \mu \mathrm{mol} \mathrm{m} \mathrm{m}^{-1} \mathrm{~d}^{-2}$. The main driver of D_Ba depletion is thought to be P_Ba barite precipitation during organic carbon remineralization [Dehairs et al., 1980; Stroobants et al., 1991; Bishop, 1988; Jeandel et al., 2000; Jacquet et al., 2007b]. Previous studies on the particulatedissolved Ba dynamics in various systems have demonstrated that $P \_B a$ cycling is up to 6 times faster than that of D_Ba due to a faster turnover time combined with smaller buildup [Jacquet et al., 2005, 2007b]. Based on this 1 to 6 ratio, we find that the P_Ba barite enrichment corresponding to the D_Ba depletion fluxes reaches up to $0.21 \mu \mathrm{mol} \mathrm{m} \mathrm{m}^{-2} \mathrm{~d}^{-1}$. These fluxes are in reasonable agreement with $\mathrm{P} \_$Ba barite fluxes estimated from sediment traps in the Northwestern Mediterranean Sea (Dyfamed station) ( 0.27 to $0.36 \mu \mathrm{mol} \mathrm{m}^{-2} \mathrm{~d}^{-1}$ at $200 \mathrm{~m}$ and $1000 \mathrm{~m}$, respectively) [see Sternberg et al., 2007] and in the Alboran Sea (0.39 to $1.07 \mu \mathrm{mol} \mathrm{m}^{-2} \mathrm{~d}^{-1}$ [Sanchez-Vidal et al., 2005]. Our D_Ba subtraction fluxes are probably subject to large uncertainties since equation (8) uses the mean age of the water masses (i.e., the average time since the water was last in contact with the atmosphere), while the processes driving the D_Ba depletion most likely occurs on much faster time scales (phytoplankton growth season).

We convert these $P \_B a$ barite fluxes into carbon fluxes using the empirically derived relationship, which relates the P_Ba barite content to oxygen consumption rate and the $\mathrm{O}_{2} / \mathrm{C}$ Redfield ratio [Dehairs et al., 1997]. The P_Ba-based organic carbon remineralization rates in the mesopelagic region are 13 and $14 \mathrm{mmol} \mathrm{C} \mathrm{m}^{-2} \mathrm{~d}^{-1}$ in the western and eastern basins. However, we note that the upper $150 \mathrm{~m}$ of the water column corresponds to the area where the POMP-derived water mass fractions are the most uncertain. In the deep western Mediterranean Sea, this flux is $29 \mathrm{mmol} \mathrm{C} \mathrm{m}^{-2} \mathrm{~d}^{-1}$. These results are in the range of previously published organic carbon fluxes in the Mediterranean Sea from sediment trap ([Sternberg et al., 2007; Sanchez-Vidal et al., 2005] and from thorium-derived data [Speicher et al., 2006; Miquel et al., 2011]. Our results are also in good agreement with recent POC flux estimates combining drifting sediment traps and underwater vision profilers [Ramondenc et al., 2016]. Furthermore, Guidi et al. [2009] and Ramondenc et al. [2016] reported higher values of the $b$ exponent from the Martin Curve (commonly used to represent the strength of carbon flux attenuation) in the western basin than in the eastern basin thus implying higher remineralization rate linked to larger phytoplankton size communities. While our results do not show any significant differences in the mesopelagic remineralization rate between the west and the east, they suggest an additional export pathway and subsequent remineralization driven by the winter deep convection in the western basin.

Table 4. D_Ba Depletion Flux and Parameters Definition for Equation (8)

\begin{tabular}{|c|c|c|c|c|c|c|}
\hline Position & $\begin{array}{l}\mathrm{H} \\
(\mathrm{m})\end{array}$ & $\begin{array}{c}\Gamma \\
\left(\mathrm{yr}^{-1}\right)\end{array}$ & $\begin{array}{c}{\left[D_{-}{ }^{B} a^{n c}\right]^{\text {mean }}} \\
\left(\mathrm{nmol} \mathrm{kg}^{-1}\right)\end{array}$ & $\begin{array}{l}{\left[\mathrm{D} \_\mathrm{Ba}^{\mathrm{nc}}\right]^{\min }} \\
\left(\mathrm{nmol} \mathrm{kg}{ }^{-1}\right)\end{array}$ & $\begin{array}{l}{\left[D_{-} \mathrm{Ba}^{\mathrm{nc}}\right]^{\max }} \\
\left(\mathrm{nmol} \mathrm{kg}{ }^{-1}\right)\end{array}$ & $\begin{array}{c}F_{D_{B} \mathrm{Ba}}^{\min }>F_{\mathrm{D}_{\_} \mathrm{Ba}}^{\operatorname{mean}}>F_{D_{-} \_\mathrm{max}}^{\max } \\
\left(\mu \mathrm{mol} \mathrm{m} \mathrm{m}^{-2} \mathrm{~d}^{-1}\right)\end{array}$ \\
\hline Meso West & 200 & 70 & -12 & -10 & -19 & $-0.08>-0.10>-0.15$ \\
\hline Meso East & 400 & 15 & -12 & -6 & -17 & $-0.45>-0.90>-1.28$ \\
\hline Deep West & 1000 & 200 & -7 & -5 & -9 & $-0.07>-0.10>-0.13$ \\
\hline
\end{tabular}

${ }^{\mathrm{a}} \mathrm{H}$ is the thickness of the anomaly. $\Gamma$ is the mean age of the water masses based on transient tracer. 


\section{Conclusions}

We have built a simple parametric water mass analysis to reconstruct the contribution of the different Mediterranean water masses to the thermohaline structure of hydrographic data collected during the M84/3 cruise. These water mass fractions have then been used to successfully reconstruct a background D_Ba field. This background field reflects the action of the large-scale oceanic circulation in maintaining the vertical gradient of D_Ba over long time scales. Our results show that the observed D_Ba field presents several regions departing significantly (positively or negatively) from this background field. In particular, our work provides evidence on the implications of D_Ba in processes related to organic carbon remineralization.

\section{References}

\section{Acknowledgments}

This research was supported by the LEFE CYBER BADIMED project (2014-2015). L. Jullion acknowledges the support of the European Union via a Marie Curie fellowship (FP7-PEOPLE-2012-IEF no 328416) This work would not have been possible without the effort of the crew, officers, and scientists on board the RV Meteor during the M84/3 cruise. All data are available at http://cdiac.ornl.gov/oceans/ Coastal/Meteor_Med_Sea.html. The authors are grateful to Alan Shiller, an anonymous reviewer, and the Editor for significantly improving the quality of the original manuscript.
Adloff, F., et al. (2015), Mediterranean Sea response to climate change in an ensemble of twenty first century scenarios, Clim. Dyn., 45 , 2775-2802, doi:10.1007/s00382-015-2507-3.

Bertram, M., and J. Cowen (1997), Morphological and compositional evidence for biotic precipitation of marine barite, J. Mar. Res., 55(3), 577-593.

Bishop, J. K. B. (1988), The barite-opal-organic carbon association in oceanic particulate matter, Nature, 332(6162), 341-343, doi:10.1038/332341a0

Broecker, W. S. (1974), “NO”, a conservative water-mass tracer, Earth Planet. Sci. Lett., 23(1), 100-107.

Cardinal, D., F. Dehairs, T. Cattaldo, and L. André (2001), Geochemistry of suspended particles in the Subantarctic and Polar Frontal zones south of Australia: Constraints on export and advection processes, J. Geophys. Res., 106, 31,637-31,656, doi:10.1029/2000JC000251.

Cardinal, D., N. Savoye, T. W. Trull, L. André, E. E. Kopczynska, and F. Dehairs (2005), Variations of carbon remineralisation in the Southern Ocean illustrated by the baxs proxy, Deep Sea Res., Part I, 52(2), 355-370, doi:10.1016/j.dsr.2004.10.002.

Chan, L. H., D. Drummond, J. M. Edmond, and B. Grant (1977), On the barium data from the Atlantic GEOSECS expedition, Deep Sea Res., 24(7), 613-649, doi:10.1016/0146-6291(77)90505-7.

Collier, R., and J. Edmond (1984), The trace element geochemistry of marine biogenic particulate matter, Prog. Oceanogr., 13(2), 113-199, doi:10.1016/0079-6611(84)90008-9.

de Brauwere, A., S. H. M. Jacquet, F. De Ridder, F. Dehairs, R. Pintelon, J. Schoukens, and W. Baeyens (2007), Water mass distributions in the Southern Ocean derived from a parametric analysis of mixing water masses, J. Geophys. Res., 112, C02021, doi:10.1029/2006JC003742.

Dehairs, F., R. Chesselet, and J. Jedwab (1980), Discrete suspended particles of barite and the barium cycle in the open ocean, Earth Planet. Sci. Lett., 49(2), 528-550, doi:10.1016/0012-821X(80)90094-1.

Dehairs, F., C. E. Lambert, R. Chesselet, and N. Risler (1987), The biological production of marine suspended barite and the barium cycle in the Western Mediterranean Sea, Biogeochemistry, 4(2), 119-140, doi:10.1007/BF02180151.

Dehairs, F., D. Shopova, S. Ober, C. Veth, and L. Goeyens (1997), Particulate barium stocks and oxygen consumption in the Southern Ocean mesopelagic water column during spring and early summer: Relationship with export production, Deep Sea Res., Part II, 44(1), 497-516, doi:10.1016/S0967-0645(96)00072-0.

Dehairs, F., N. Fagel, A. Antia, R. Peinert, M. Elskens, and L. Goeyens (2000), Export production in the Bay of Biscay as estimated from barium barite in settling material: A comparison with new production, Deep Sea Res., Part I, 47(4), 583-601, doi:10.1016/S0967-0637(99)00072-2

Dehairs, F., et al. (2008), Barium in twilight zone suspended matter as a potential proxy for particulate organic carbon remineralization: Results for the North Pacific, Deep Sea Res., Part II, 55(14), 1673-1683, doi:10.1016/j.dsr2.2008.04.020.

Ganeshram, R. S., R. François, J. Commeau, and S. L. Brown-Leger (2003), An experimental investigation of barite formation in seawater, Geochim. Cosmochim. Acta, 67(14), 2599-2605, doi:10.1016/S0016-7037(03)00164-9.

Gruber, N., and J. Sarmiento (1997), Global patterns of marine nitrogen fixation and denitrification, Global Biogeochem. Cycles, 11(2), 235-266, doi:10.1029/97GB00077.

Guidi, L., et al. (2009), Effects of phytoplankton community on production, size, and export of large aggregates: A world-ocean analysis, Limnol. Oceanogr., 54, 1951-1963.

Hainbucher, D., A. Rubino, V. R. Cardin, T. Tanhua, K. Schroeder, and M. Bensi (2013), Hydrographic situation during cruise M84/3 and P414 (spring 2011) in the Mediterranean Sea, Ocean Sci., 10(6), 2399-2432.

Hoppema, M., F. Dehairs, J. Navez, C. Monnin, C. Jeandel, E. Fahrbach, and H. J. W. de Baar (2010), Distribution of barium in the Weddell Gyre: Impact of circulation and biogeochemical processes, Mar. Chem., 122(1), 118-129, doi:10.1016/j.marchem.2010.07.005.

Horner, T. J., C. W. Kinsley, and S. G. Nielsen (2015), Barium-isotopic fractionation in seawater mediated by barite cycling and oceanic circulation, Earth Planet. Sci. Lett., 430, 511-522, doi:10.1016/j.epsl.2015.07.027.

Jacquet, S. H. M., F. Dehairs, D. Cardinal, J. Navez, and B. Delille (2005), Barium distribution across the Southern Ocean frontal system in the Crozet-Kerguelen Basin, Mar. Chem., 95(3), 149-162, doi:10.1016/j.marchem.2004.09.002.

Jacquet, S. H. M., J. Henjes, F. Dehairs, A. Worobiec, N. Savoye, and D. Cardinal (2007a), Particulate Ba-barite and acantharians in the Southern Ocean during the European Iron Fertilization Experiment (EIFEX), J. Geophys. Res., 112, G04006, doi:10.1029/2006JG000394.

Jacquet, S. H. M., F. Dehairs, M. Elskens, N. Savoye, and D. Cardinal (2007b), Barium cycling along WOCE SR3 line in the Southern Ocean, Mar. Chem., 106(1), 33-45, doi:10.1016/j.marchem.2006.06.007.

Jacquet, S. H. M., N. Savoye, F. Dehairs, V. H. Strass, and D. Cardinal (2008a), Mesopelagic carbon remineralization during the European Iron Fertilization Experiment, Global Biogeochem. Cycles, 22, GB1023, doi:10.1029/2006GB002902.

Jacquet, S. H. M., F. Dehairs, N. Savoye, I. Obernosterer, U. Christaki, C. Monnin, and D. Cardinal (2008b), Mesopelagic organic carbon remineralization in the kerguelen plateau region tracked by biogenic particulate Ba, Deep Sea Res., Part II, 55(5), 868-879, doi:10.1016/j.dsr2.2007.12.038.

Jacquet, S. H. M., P. J. Lam, T. Trull, and F. Dehairs (2011), Carbon export production in the subantarctic zone and polar front zone south of Tasmania, Deep Sea Res., Part II, 58(21), 2277-2292, doi:10.1016/j.dsr2.2011.05.035.

Jacquet, S. H. M., et al. (2015), Early spring mesopelagic carbon remineralization and transfer efficiency in the naturally iron-fertilized Kerguelen area, Biogeosciences, 12(6), 1713-1731, doi:10.5194/bg-12-1713-2015.

Jacquet, S. H. M., C. Monnin, V. Riou, L. Jullion, and T. Tanhua (2016), A high resolution and quasi-zonal transect of dissolved Ba in the Mediterranean Sea, Mar. Chem., 178, 1-7.

Jeandel, C., B. Dupré, G. Lebaron, C. Monnin, and J. F. Minster (1996), Longitudinal distributions of dissolved barium, silica and alkalinity in the Western and Southern Indian Ocean, Deep Sea Res., Part I, 43(1), 1-31, doi:10.1016/0967-0637(95)00098-4. 
Jeandel, C., K. Tachikawa, A. Bory, and F. Dehairs (2000), Biogenic barium in suspended and trapped material as a tracer of export production in the tropical NE Atlantic (Eumeli sites), Mar. Chem., 71(1-2), 125-142, doi:10.1016/S0304-4203(00)00045-1.

Lacan, F., and C. Jeandel (2005), Neodymium isotopes as a new tool for quantifying exchange fluxes at the continent-ocean interface, Earth Planet. Sci. Lett., 232(3-4), 245-257, doi:10.1016/j.epsl.2005.01.004.

Lea, D., and E. Boyle (1989), Barium content of benthic foraminifera controlled by bottom-water composition, Nature, 338(6218), 751-753, doi:10.1038/338751a0.

Lea, D. W. (1993), Constraints on the alkalinity and circulation of glacial circumpolar deep water from benthic foraminiferal barium, Global Biogeochem. Cycles, 7(3), 695-710, doi:10.1029/93GB01536.

Malanotte-Rizzoli, P., et al. (2014), Physical forcing and physical/biochemical variability of the Mediterranean Sea: A review of unresolved issues and directions for future research, Ocean Sci., 10(3), 281-322.

Millot, C., and I. Taupier-Letage (2005), Circulation in the Mediterranean Sea, in The Handbook of Environmental Chemistry, vol. 5, edited by C. Millot and I. Taupier-Letage, pp. 29-66, Springer, Berlin, doi:10.1007/b107143.

Miquel, J., J. Martín, B. Gasser, A. Rodriguez-y Baena, T. Toubal, and S. Fowler (2011), Dynamics of particle flux and carbon export in the northwestern Mediterranean Sea: A two decade time-series study at the dyfamed site, Prog. Oceanogr., 91(4), 461-481.

Monnin, C., and D. Cividini (2006), The saturation state of the world's ocean with respect to (Ba,Sr)SO4 solid solutions, Geochim. Cosmochim. Acta, 70(13), 3290-3298, doi:10.1016/j.gca.2006.04.002.

Monnin, C., C. Jeandel, T. Cattaldo, and F. Dehairs (1999), The marine barite saturation state of the world's oceans, Mar. Chem., 65(3), 253-261, doi:10.1016/S0304-4203(99)00016-X.

Moutin, T., and P. Raimbault (2002), Primary production, carbon export and nutrients availability in western and eastern Mediterranean Sea in early summer 1996 (MINOS cruise), J. Mar. Syst., 33-34, 273-288.

Pujo-Pay, M., P. Conan, L. Oriol, V. Cornet-Barthaux, C. Falco, J. F. Ghiglione, C. Goyet, T. Moutin, and L. Prieur (2011), Integrated survey of elemental stoichiometry (C, N, P) from the western to eastern Mediterranean Sea, Biogeosciences, 8(4), 883-899.

Ramondenc, S., M. Goutx, F. Lombard, C. Santinelli, L. Stemmann, G. Gorsky, and L. Guidi (2016), An initial carbon export assessment in the Mediterranean Sea based on drifting sediment traps and the Underwater Vision Profiler data sets, Deep Sea Res., 117, 107-119, doi:10.1016/j.dsr.2016.08.015.

Roether, W., B. Klein, B. Manca, A. Theocharis, and S. Kioroglou (2007), Transient Eastern Mediterranean deep waters in response to the massive dense-water output of the Aegean Sea in the 1990s, Prog. Oceanogr., 74(4), 540-571.

Sanchez-Vidal, A., R. W. Collier, A. Calafat, J. Fabres, and M. Canals (2005), Particulate barium fluxes on the continental margin: A study from the Alboran Sea (Western Mediterranean), Mar. Chem., 93, 105-117.

Santinelli, C., L. Nannicini, and A. Seritti (2010), DOC dynamics in the meso and bathypelagic layers of the Mediterranean Sea, Deep Sea Res., Part II, 57(16), 1446-1459, doi:10.1016/j.dsr2.2010.02.014.

Schneider, A., T. Tanhua, W. Roether, and R. Steinfeldt (2014), Changes in ventilation of the Mediterranean Sea during the past 25 year, Ocean Sci., 10(1), 1-16.

Schroeder, K., A. Ribotti, M. Borghini, R. Sorgente, A. Perilli, and G. P. Gasparini (2008), An extensive western Mediterranean deep water renewal between 2004 and 2006, Geophys. Res Lett., 35, L18605, doi:10.1029/2008GL035146.

Schroeder, K., S. A. Josey, M. Herrmann, L. Grignon, G. P. Gasparini, and H. L. Bryden (2010), Abrupt warming and salting of the Western Mediterranean Deep Water after 2005: Atmospheric forcings and lateral advection, J. Geophys. Res., 115, C08029, doi:10.1029/2009JC005749.

Schroeder, K., et al. (2013), Long-term monitoring programme of the hydrological variability in the Mediterranean Sea: A first overview of the HYDROCHANGES network, Ocean Sci., 9(2), 301-324.

Somot, S., F. Sevault, and M. Déqué (2006), Transient climate change scenario simulation of the Mediterranean Sea for the twenty-first century using a high-resolution ocean circulation model, Clim. Dyn., 27(7-8), 851-879.

Speicher, E. A., S. B. Moran, A. B. Burd, R. Delfanti, H. Kaberi, R. P. Kelly, and C. Papucci (2006), Particulate organic carbon export fluxes and size-fractionated POC/234th ratios in the Ligurian, Tyrrhenian and Aegean Seas, Deep Sea Res., 53(11), 1810-1830, doi:10.1016/j.dsr.2006.08.005.

Sternberg, E., C. Jeandel, J.-C. Miquel, B. Gasser, M. Souhaut, R. Arraes-Mescoff, and R. Francois (2007), Particulate barium fluxes and export production in the Northwestern Mediterranean, Mar. Chem., 105(3), 281-295, doi:10.1016/j.marchem.2007.03.003.

Stöven, T., and T. Tanhua (2014), Ventilation of the Mediterranean Sea constrained by multiple transient tracer measurements, Ocean Sci., 10(3), 439-457, doi:10.5194/os-10-439-2014.

Stroobants, N., F. Dehairs, L. Goeyens, N. Vanderheijden, and R. Van Grieken (1991), Barite formation in the Southern Ocean water column, Mar. Chem., 35(1), 411-421, doi:10.1016/S0304-4203(09)90033-0.

Tanhua, T., D. Hainbucher, K. Schroeder, V. R. Cardin, M. Alvarez, and G. Civitarese (2013a), The Mediterranean Sea system: A review and an introduction to the special issue, Ocean Sci., 9(5), 789-803.

Tanhua, T., D. Hainbucher, V. Cardin, M. Alvarez, G. Civitarese, A. P. McNichol, and R. M. Key (2013b), Repeat hydrography in the Mediterranean Sea, data from the meteor cruise 84/3 in 2011, Earth Syst. Sci. Data, 5(2), 289-294, doi:10.5194/essd-5-289-2013.

Tomczak, M. (1981), A multi-parameter extension of T-S diagram techniques for the analysis of non-isopycnal mixing, Prog. Oceanogr., 10, $147-171$.

Tsimplis, M., et al. (2006), Changes in the oceanography of the Mediterranean Sea and their link to climate variability, in Mediterranean Climate Variability, edited by M. Tsimplis et al., pp. 227-282, Elsevier, Amsterdam, Netherlands. 